\title{
LAGEB MUBATTIN
}

\author{
Muhammad Fabian Arrizqi \\ Program Pascasarjana ISI Yogyakarta
}

\begin{abstract}
Abstrak
Fenomena sosial didefinisikan sebagai peristiwa yang menjadi hits di antara orang-orang, dalam hal ini, begal. Begal adalah individu atau kelompok yang melakukan kejahatan dengan menyita properti orang lain dengan menggunakan kekuatan atau tidak ada kekuatan. Dalam hal ini, perampok adalah sosok yang korup.Grafter adalah pengertian sempit yang menipu seseorang atau sekelompok pejabat negara yang memanfaatkan miliknya untuk mengambil keuntungan dari posisi tersebut.

Talo balak adalah salah satu tradisi ansambel Lampung yang terdiri dari seperangkat klittang, kecrek, canang, bende, dokdok, gong dan kempul.

Komposisi musik etnik adalah perwujudan proyek yang akan menghadirkan penulis. Mengenai metode tarian, kreasi diprakarsai oleh Alma M. Hawkins, komposisi ini akan menampilkan sesuatu yang baru seperti-ritme, pola melodi, bentuk musik, serta komposisi instrumen dalam repertoar penciptaan musik etnis.
\end{abstract}

kata kunci: fenomena sosial, talo balak, komposisi musik etnis.

\begin{abstract}
The social phenomenon defined as events that are hits among the people, in this case, begal. Begal is individuals or groups who commit the crime by seizing the property of another using force or no force. In this case, the robber is a corrupt figure. Grafter is the narrow sense is cheating a person or group of state officials who take advantage of not hers or his to take advantage of the position.

Talo balak is one tradition Lampung ensemble consisting of a set of klittang, kecrek, canang, bende, dokdok, gong and kempul.

Ethnic music composition is a manifestation of projects that will present the author. Regarding the method of dance, creation was initiated by Alma M. Hawkins, this composition will show something new like-rhythmic, melodic patterns, forms of music, as well as the composition of instruments in the repertoire of ethnic music creation.
\end{abstract}

keywords: the social phenomenon, talo balak, ethnic music composition. 


\section{Pendahuluan}

Fenomena sosial yang marak terjadi di negeri ini adalah begal. Hampir seluruh media masa nasional memunculkan headline mengenai begal. Begalmotor dijalanan sampai begal anggaran yang di lakukan oleh anggota dewan di ibukota sedangramaidiperbincangkansaatini.Begal dalamkamusbesarbahasaIndonesia memiliki arti penyamun (perampok). Segala kegiatan yang berhubungan dengan merampas,merampok,mengambilhakorang laindapatdisebutdenganbegal(Tim

Penyusun, 2008, 156). Begal itu ada bermacam-macam.Ada yang bergelar "begal biasa" dan ada yang bergelar "begal berdasi". Nama tersebut penulis bedakan berdasarkan tempat dan apa yang ia rampas. Begal biasa adalah perampok yang biasanya merampas barang-barang pribadi orang dan biasanya terjadi dijalan-jalan sepi.Sedangkanbegalberdasiataubisadisebu tbegalelitinimerampokatau membegal anggaran.Koruptor merupakan wujud sosok "begal berdasi" atau sosok kriminal pintar yang lihai, licin dan kejam.

Sejarah menjelaskan bahwa Aristoteles mengingatkan bahwa, semakin tinggi penghargaan manusia terhadap kekayaan (uang), maka semakin rendahlah penghargaan manusia terhadap nilai-nilai kebenaran, kesusilaan, keadilan dan kepatutan (aristoteles). Segala cara dilakukan agar bisa mendatangkan uang. Dari carayang baik sampai cara yang tidak baikpun dilakukan. Fenomena begal ini menarik untuk diangkat sebagai tema dalam komposisi musik, selain karena masih hangat diperbincangkan, juga terjadi hampir diseluruh lapisan masyarakat.Walaupun realitas begal sendiri telah eksis jauh-jauh hari sebelum fenomenabegal mencuat besar-besaran di berbagai daerah diIndonesia.

Berdasarkan paparan diatas, maka penulis berkeinginan untuk mentransfer fenomena begal kedalam suatu bentuk garapan musik etnis.Dengan berbagai pencarian serta pertimbangan, maka karya ini diberi judul "Lageb Mubatin”. Kata Lageb diambil dari kata begal yang dieja terbalik.Sedangkan kata Mubatin yangdiambildaribahasaLampungdanmemil ikiartikaya(iksar,2013,40).Untuk itu Lageb Mubattin dapat diartikan sebagai kejahatan berupa merampas atau merampok uang rakyat, sehingga begal berdasi atau lazim disebut koruptor ini memiliki harta kekayaan yang luar biasa.Dengan demikian koruptor dalam komposisimusikinidisebutsebagaiLagebM ubattindansekaligusdipakaisebagai temalagu.

Uraian diatas diketahui, bahwa begal merupakan fenomena sosial masyarakat yang cenderung bersifat negatif. Berdasarkan latar belakang ide yang sudah dipaparkan tersebut, tema yang ingin disampaikan adalah fenomena sosial yaitu begal. Berbagai macam cara dilakukan oleh gerombolan pembegal untuk melakukan aksinya. Dari fenomena sosial tersebutlah penulis mendapatkan inspirasi, serta merangsang daya kreativitas dalam karya ini.Selanjutnyadijadikan ide musikal dalam bentuk karya musik etnis dengan tema fenomena sosial begal. Namun, bagaimana cara mengaplikasikan begal kedalam bentuk komposisi musik etnis. Hal ini lah yang akan dilakukan penulis dalam karya tugas akhir penciptaan musik etnis. 


\section{Ekranisasi-Dekranisasi-Habitus}

Ekranisasi oleh Erneste (1991) memberikan sebuah penjelasan bahwa ekranisasi berasal dari kata ekran artinya layar putih, berdasarkan pengertian ini bahwa ekranisasi adalah mengambil sebuah pemahaman mengubah tulisan atau sastra ke film atau layar lebar, tetapi dalam perkembangan ada konsep yang ditawarkanmengenai dekranisasi sebuah fenomena mengembalikan konteks film ke dalam wujud aslinya.

Kata layar putih sebagai sebuah wadah, dalam tinjauan Bordieu (1990) mengenai arena, modal dan habitus tidak harus sebuah yang identik dengan film, konsep layar bisa dikembangkan dalam ranah musikal karena bersifat abstrak. Proses pengalihwahanaan sebuah fenomena sosial berupa habitus menjadi karya musik justru menjadi konsep bahwa habitus merupakan perilaku masyarakat dalam aktivitas sehari-hari yang mencerminkan jati diri.

\section{Metode Penelitian Penciptaan}

Practice as Research merupakan sebuah metode yang digunakan untuk menyatakan bahwa praktek itu sendiri adalah sebuah penelitian. Metode dalam konteks etnomusikologi bidang penciptaan dalam penelitian ini mengadopsi darimetode yang dilakukan yang dikemukaan oleh Alma. M. Hawkins yaitu eksploration (penjajagan), improvitation (percobaan), dan forming (pembentukan). Hadi, (2011: 70). Aplikasi metode tersebut dikembangkan melalui daya kreativitas musikal penulis, dengan mengkombinasikan trial error Edward Lee Thorndike mengenai eksprerimen sehingga membentuk tahapan penciptaan musik sebagai sebuah penelitian.

\section{Eksplorasi}

Eksplorasiyaitusuatupenjajaganterha dapobyekataufenomenayangberasal dariluardirinya.Suatupengalamanyangmen dapatkanrangsangan,sehinggadapat memperkuat kreativitas.Eksplorasi termasuk memikirkan, mengimajinasikan, merenungkan, merasakan, dan juga merespon objek - objek atau fenomena alam yang ada.Hadi(2011: 70) Penentuan data - data lisan, tulisan, dan diskografi merupakan salah satu langkah awal untuk melakukan proses eksplorasi. Proses ini akan terus berjalan sesuai dengan totalitas komposer, dengan kata lain tidak hanya dilakukan pada awal sebelum komposisi dibuat, tetapi sampai tahap evaluasi. Metode eksplorasi dibagi menjadi dua, non musikal danmusikal.

Pertama, eksplorasi nonmusikal dilakukan untuk menentukanelemenelemen non musikal meliputi rangsang awal, rancangan bentuk garapan, rumusan ide penciptaan, tema, dan judul.Fenomena begal menjadi sebuah pertanyaan untuk memunculkan rumusan ide penciptaan. Rangsangan audio-visual dan data lisan, tulisan, diskografi yang berkaitan dengan kajian "Lageb Mubatin ", dapat menjadi objek dalam pembentukan melodi, harmoni, dinamika, dan lagu. Proses ini dilakukan dengan berbagai cara mulai dari berfikir, mencari sumber penciptaan baik lisan maupun tulisan, menganalisis data, dan mengevaluasidata.

Penemuan rumusan ide penciptaan, tema, judul yang sesuai, langkah berikutnya melakukan penggalian musikal dengan metode eksplorasi. Proses eksplorasi musikal karya ini dibagi menjadi : 


\section{Eksplorasi Bunyi}

Mengamati

dan mencoba membunyikan hal-hal non musikal dan musikal.Setelah hasil eksplorasi itu terkumpul maka penulis mulai membuat kerangka melodi yang sesuai dengan suasana yang terjadi menurut interpretasi penulis.

\section{Eksplorasi Suasana}

Mengamati suasana yang cocok terhadap karya yang akan disajikan. Penulis mengamati berbagai macam pertunjukan yang menggunakan berbagai macam suasana untuk mencari kemungkinan-kemungkinan yang cocok terhadap karya yang akan penulis sajikan. Pengolahan eksplorasi suasana ditekankan pada

alurdinamikakomposisiyangakandisajikan. Prinsipnya,suasanayangdiolahtetap pada jalur yang sesuai dengan tema yaitu nafas kehidupan.Suasana yang disajikan meliputi suasana tenang, damai, senang, konflik, chaos, dan sedih. Suasana yang dihasilkan tidak akan tersampaikan kepada penonton apabila ekspresi musikal dari suasana tersebut tidak diimbangi dengan ekspresi musikalpemain.

\section{Eksplorasi Bentuk}

Mengamati bentuk yang sesuai dengan karya yang akan disajikan. Dalam melakukan eksplorasi bentuk, penulis membiasakan diri untuk lebih peka terhadap segala bentuk kejadian ataupun fenomena dan menerima segala rangsangan yang masuk kedalam pancaindra serta mengaplikasikan ke dalam karya.Eksplorasi bentuk dalam karya ini dimulai dengan eksplorasi pada bunyi yang hadir saat kejadian berlangsung.

\section{Ekspolorasi Teknik}

Eksplorasi teknik dalam karya ini lebih kepada proses melakukan sesuatu agar mendapatkan hasil yang diinginkan oleh penulis. Eksplorasi teknik banyak diterapkan dalam proses pencarian warna suara yang baru terhadap instrumen dan juga pencarian melodi dalam karya ini, agar sesuai dengan kebutuhan penata dan tingkat kemampuan musisi.

\section{Improvisasi}

Langkah awal improvisasi adalah melakukan berbagai macam uji coba untukmenentukannadaataubunyiyangdiingi nkan.Improvisasiberikutnyaadalah pencarian teknik permainan seperti yang lazim dipakai dalam musik Barat seperti repetisi (pengulangan), filler (isian), skuens (gerak searah), elise(pengurangan), dan improvisasi secara bebas. Pada metode ini juga terdapat beberapa pengembangan atau penambahan pada motif-motif ritmis dan melodi sebelumnya.Selain itu penyaji juga melakukan improvisasi pada bagianbagian tertentu hanya untuk mengisi kekosongan serta menunjukan Virtuoso (keterampilan).Disamping itu improvisasi berarti menciptakan sesuatu yang diperagakan secara langsung pada saat itu juga (Mack, 1995, 162).Dari kesekian hal tersebut dilakukan karena penyaji merasa belum puas dan daya pikirnya selalu berkembang waktu demi waktu tetapi dari ketidakpuasan tersebut pada akhirnya penyaji sendiri harus bias membatasinya agar komposisi tersebut bisa segera terbentuk.

Improvisasi dalam karya ini lebih sering hadir pada proses pembuatan karya dan latihan. Improvisasi menjadikan karya yang penulis buat lebih fleksibel karena 
pertimbangan saat proses pembuatan karya kadang tidak sesuai ketika diterapkan pada instrumen sehingga penulis harus berimprovisasi agar proses latihan bisa lancar dan sesuai dengan yang diharapkan. Improvisasi dapat dikaitkan dengan eksplorasi, sehingga menjadi satu kesatuan proses komposisi yang terstruktur ( hadi, 2013, 77).

Tahapan improvisasi inilah penulis memasukkan konsep trial error Thorndike dalam suatu ruang eksperimental sehingga diperoleh unsur refleksi dalam penelitian penciptaan karya musik etnis.

\section{a. Pembentukan}

Penciptaan musik ini berpedoman pada terwujudnya keindahan yang didasari oleh keutuhan, penonjolan, dan keseimbangan sebagai satu kesatuan. Prosesinitidakbersifatstatis,dalamartimasih memberikanruanggerakkreatifitas untuk menafsirkan isian melodi-melodi pokok yang diperlukan. Penciptaan musik etnis diwujudkan dalam bentuk komposisi musik. Selanjutnya dalam proses penciptaanini,penulismasihdiberiruangdan waktukreativitasuntukmenuangkan ide ke dalam isian-isian melodi, ritme, dan harmoni. Dalam komposisi musik ini, setiap instrumen telah memiliki melodi dan ritmenya masing-masing walaupun dimainkan secara berulang-ulang.Namun semuanya berperan sebagai kesatuan ruang dan waktu dalam komposisi ini, sehingga keutuhan tersebut dapat dihayati dan dimengerti olehpenikmat.

Komposisi dibentuk dengan variasi yang pengulangannya cenderung tidak sama dengan sebelumnya. Hal tersebut dimaksudkan agar komposisi ini tidak mudah ditebak ketika mau perpindahan ke movement selanjutnya, tetapi variasi tersebut masih dalam unsur-unsur yang telah ditentukan.Variasi, seperti pola pernafasan manusia yang selalu berbeda disetiap hari.Hal ini selalu berubah dan sangat berkaitan dengan pikiran, perasaan, imajinasi, dan pengalaman, serta aktivitas fisik (McDermott, 2013, 57).

Penyusunan komposisi ditekankan pada garis dramatik yang berhubungan dengandinamikapertunjukan.Singkatnya,m enyusunsuatukomposisimusikharus

terstruktur, supaya dinamika yang diinginkan dapat terealisasikan.Penyusunan komposisi mengacu ada aspek - aspek musikal meliputi melodi, harmonisasi, dinamika, dan tempo. Berbagai aspek tersebut diolah atau disusun dengan variasi sukat, nilai nada, dan lainlain.

Skema Practice as Research "Lageb Mubattin"

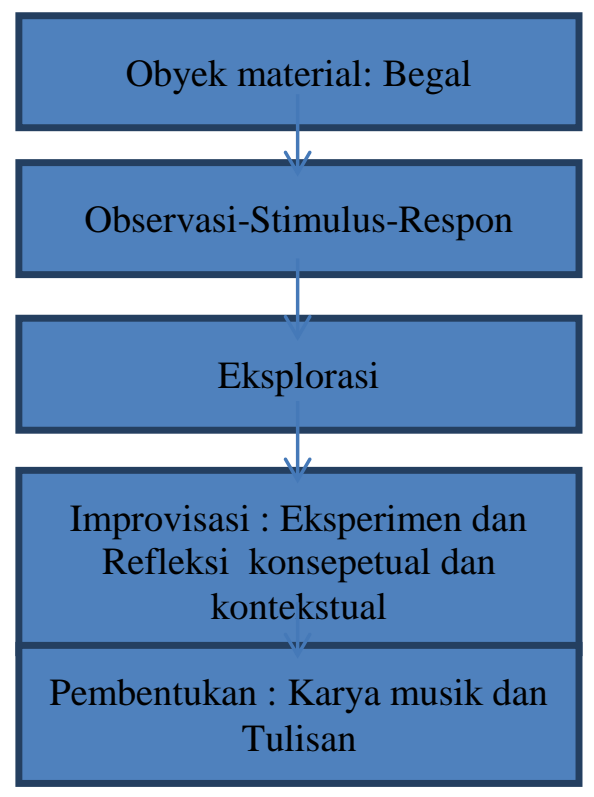

Skema 1

Practice as research di adopsi, dikembangkan dari Hawinks dan Thorndike 


\section{Pembahasan}

Habitus atau perilaku merupakan salah satu unsur kebudayaan dalam aspek tinjauan ilmu komunikasi bidang persepsi sosial. Begal dalam kata lain adalah rampok merupakan sebuah perilaku negatif yang merusak jati diri pribadi, masyarakat, bangsa dan negara. Tetapi adanya begal dalam aktivitas masyarakat ternyata tidak lepas dari ketimpangan ekonomi sosial yang dialami oleh masyarakat dalam sebuah arena; misalkan susahnya lapangan pekerjaan; kurangnya mempunyai modal budaya dan pengetahuan bahkan kekurangmampuan pemangku kebijakan dalam meratakan pendapatan.

Begal sebagai sebuah perilaku negatif dapat diilustrasikan sebagai suatu habitus yang keras, menakutkan, sangar sehingga ilustrasi tersebut dapat dialihwahanakan ke dalam sebuah wadah atau layar putih bernama musik.

Musik adalah ekspresi keindahan yang menggunakan bunyi-bunyian sebagai media pengungkapanya.Bunyi-bunyian diolah dan diatur sedemikian rupa sehingga membentuk struktur yang tersusun berdasarkan peran dan fungsinya didalam musik.Sebagai peran, struktur bunyi tersebut dapat menduduki peran utama, namun juga dapat sebagai pendukung.sementara struktur bunyi dapat berfungsi sebagai melodi, sebagai ritme, maupun sebagai harmoni. kesatuan struktur bunyi-bunyian, baik melodi, ritme, maupun harmoni dapat disebut sebagai bahan dasar musik.

Bahan dasar musik tersebut tidak akan sampai pada penonton jika tidak memakai

mediapengungkapanyanglazimdisebutseba gaiinstrumenmusik,baikvokalmaupunalatalat musik. Pemilihan alat musik sebagai media ekspresi, bukanlah sebuah pekerjaan yang mudah. Ketepatan didalam menyeleksi alat musik yang dipakai akan menentukan keberhasilan dalam menyampakan sajian musik kepadapenonton.

Proses kreatif penulis dalam mengkomposisi karya begal ini berupaya mentransformasikan hal-hal yang berkaitan dengan begal kedalam bentuk musikal, yaitu denganmengolahprosesipembegalanyangte lahmelewatiproseskreatifpenulissehingga didapatkan istilah membegal perhatian, dengan kata lain merampas perhatianaudien.

Berbagai macam hasil kreatif tersebut sangat penting dalam komposisi musik etnis ini karena digunakan sebagai idiom musikal, sementara bentuk musik sebagai medium musikalnya. Komposisi tentang begal ini terdiri atas beberapa bagian yaitu : bagian I eksposisi,bagianIIdevelopmen,bagianIIIrek apitulasi,sertaintroduksidancoda.Bentuk komposisimusiktigabagianinilazimdisebut bentukSonatadalamkomposisimusikBarat.

Pengolahan serta pemilihan tangga nada sangat diperhitungkan dengan seksama. Karena frame yang terbentuk tiap kalimat lagu sangat mempengarui nuansa yang ditimbulkan pada setiap bagian. Pada bagian intro, penulis memilih permainan kecapi Sunda yang memainkan tangga nada minor sebagai peran utama yang mengadopsi pola serta tehnik permainan Qanun.Alat music yang memegang peran pendukung seperti accordeon, floor-tom, cymbal, marchingbell, seruling, serta bass elektric.Komposisi bagian I merupakan perkenalan begal yang terdiri atas 6 motif yang masing-masing motif merupakan 
perwujudan dari begal yang dibuat seolaholah angka maka akan didapatkan angka 83-6-4-7 yang nantinya akan diolah menjadi nada-nada yang dimainkan tiap motif bagian I ini. Dari pola tabuh tersebut divariasi melodi yang dimainkan oleh klittang yang memainkan lagu pokok dan diiringi oleh instrument lainya. Beberapa tehnik yang digunakan pada bagian pertama ini antara lain isian, pengulangan, elise, serta imitasi. Berikut adalah notasi pada bagian pertama.

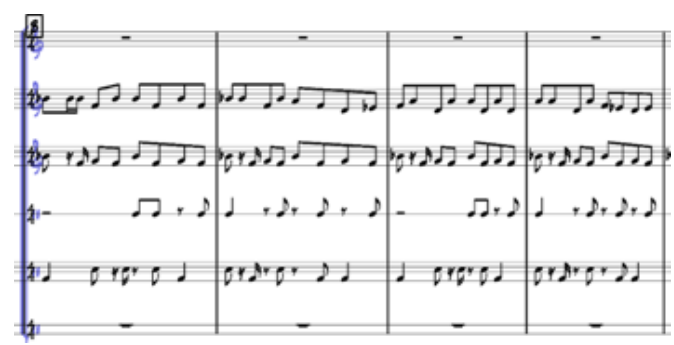

Melodi utama dimainkan oleh talo balak yang dikembangkan oleh instrumen klittang yang dimainkan dengan cara dipukul dengan pemukul bonang. Cetik memainkan melodi yang berbentuk filler dari melodi utama dimainkan dengan cara dipukul dengan stik bambu.

BagianIIakanmembicarakantentangk onflikyaituprosespembegalan itu sendiri. Secara musikal bagian II ini adalah pengembangan dari bagian I yaitu pengulangan motif yang terdapat pada bagian I yang di aransement terbalik.Keterbalikantersebutmencakupako rd,skala,urutan,sertamoodyangdirubah.Pem balikan/inversimotif

padabagianIIbertujuanuntukmemberikanw arnabarudalamkomposisisertamemperkuat konsep yang dikembangkan lebih imajinatif tentang pembegalan, pencurian, perampasan, dan lain-lain, dengan tetap mempertahankan benang merah antar bagian dan antar motif.contohnya pengulangan interpretasi begal yang menjadi angka dan disusun terbalik, maka akan didapatkan urutan 7-4-6-3-8. Tempo pada bagian II ini tak jauh berbeda dengan bagian I yaitu direntan 90- 129 bpm yang disesuaikan pada tiap motif guna membangun mood yang dikehendakipenata.

Bagian II digarap dengan menggunakan tehnik unison dan melodi utama

dibuatharmoniduasuarayaituserulingdanak ordion.Sukatyangdigunakanadalah

4/4dan6/8dengannadapertamaadalah1.Pada bagianinipenulismenggambarkan suasana gembira seorang pejabat negara.Tehnik yang digunakan pada frasa ini adalah imitasi, unisono, filler,diminusi.

Frasa selanjutnya melodi utama dimainkan oleh cetik dengan tensi yang tinggi dengan tehnik pukulan double stroke yang dikembangkan oleh pemainnya sehingga didapatkan bunyi yang menakjubkan.Melodi yang dimainkan adalah sebagai berikut.

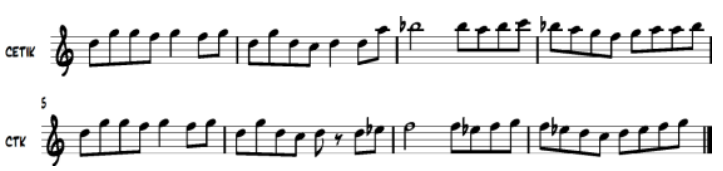

'Motif diatas diperkuat dengan unisono oleh gambus dan seruling, serta diiringi oleh klittang dan accordeon secara unisono untuk menegaskan akor.

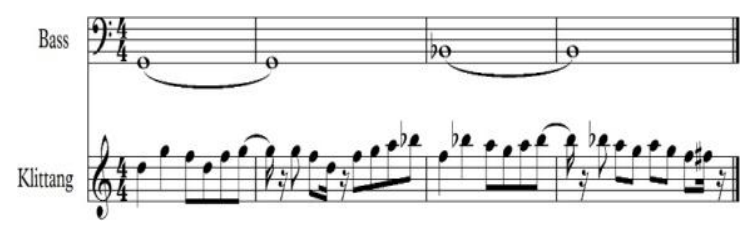

Bagian III ini penata ingin bercerita tentang kesimpulan mengenai begal yang telah diperkenalkan pada bagian I dan diekplorasi pada bagian II. Secara musikal, 
penyikapan terhadap bagian ini lebih kompleks yaitu keseluruhan motif digabungkan menjadi beberapa motif yang lebih berwarna. Bagian III ini tak lupa penata juga menempatkan aransemen motif antara bagian I dan bagian II yang mendapat perlakuan elise (prier, 1996, 70). Bentuk aransemenya juga akan mengalami sedikit perubahan tiap motif. Suasana yang diciptakaan akan lebih halus karena akan mengalami anti klimaks dengan perenungan.

Klittang memainkan pola dasar talo balak secara unisono dengan membagi harnoni 1 dan 2. Klittang dimainkan dengan cara dipukul. Seruling menggunakan tehnik filler serta diminusi yang dimainkan dengan cara sinkup. Seruling dibunyikan dengan cara ditiup.

\section{Penutup}

Musik yang berjudul Lageb Mubattin merupakan penciptaanmusic sebagai sebuah penelitian yang bersifat kritik atas fenomena sosial yang terjadi dalam kehidupan masyarakat pada saat ini. Lageb Mubattin yang tidak lain adalah koruptor ini

bercerita tentang 'aksi' yang dilakukan koruptor bersama kronikroninya telah menyebar dalam kehidupan masyarakat Indonesia, maka wajar dikatakan sebagai fenomena sosial. Atas dasar itulah keprihatinan penata muncul menjadi sebuah imajinasi yang selanjutnya diekspresikan dalam wujud seni, yang dalam hal ini adalah komposisi musik yang diberi judul Lageb Mubattin.

\section{Daftar Pustaka}

Bordieu. 1990. Essay. Toward Reflexive Sociology, Cambridge Publisity Press.

Fabian, M. Arrizqi. 2015. Skripsi "Lageb Mubbattin". Yogyakarta. Jurusan Etnomusikologi Fakultas Seni Pertunjukkan Institut Seni Indonesia Yogyakarta.

Iksar, Kamus Saku Bahasa Lampung (Bandar Lampung: Smart Cipta Intelekta, 2013)

Tim Penyususn, Ensiklopedia Indonesia Jilid 3 - Edisi Khusus (Jakarta, 1987) Banoe,

Pono, Kamus Musik (Yogyakarta: Kanisius, 2003)

Y. Sumandyo Hadi, Koreografi Bentuk Teknik Isi (Yogyakarta: Cipta Media, 2011)

Dieter Mack, SejarahMusikJilid 4( Yogyakarta: PusatMusikLiturgi, 1995)

Karl Edmund Prier SJ, Ilmu Bentuk Musik ( Yogyakarta: PML, 1996)

Vincent McDermott, IMAGI-NATION (Yogyakarta: AMT , 2013) 